BULLETIN Bulletin hispanique

HISPANIQUE Université Michel de Montaigne Bordeaux

$119-2 \mid 2017$

La Égloga renacentista en el Reino de Nápoles

\title{
La égloga en vulgar o el bucolismo en su trayectoria de Siena a Nápoles
}

\section{Mercedes López Suárez}

\section{(2) OpenEdition}

1 Journals

\section{Edición electrónica}

URL: http://journals.openedition.org/bulletinhispanique/5066

DOI: 10.4000/bulletinhispanique.5066

ISSN: 1775-3821

\section{Editor}

Presses universitaires de Bordeaux

\section{Edición impresa}

Fecha de publicación: 1 diciembre 2017

Paginación: 517-536

ISBN: 979-10-300-0218-8

ISSN: 0007-4640

\section{Referencia electrónica}

Mercedes López Suárez, "La égloga en vulgar o el bucolismo en su trayectoria de Siena a Nápoles», Bulletin hispanique [En línea], 119-2 | 2017, Publicado el 28 diciembre 2020, consultado el 14 enero 2021. URL: http://journals.openedition.org/bulletinhispanique/5066 ; DOI: https://doi.org/10.4000/ bulletinhispanique.5066 


\title{
La égloga en vulgar o el bucolismo en su trayectoria de Siena a Nápoles
}

\author{
Mercedes López SuÁrez \\ Universidad Complutense de Madrid
}

À l'origine des églogues en langue vulgaire (seconde moitié du XVe siècle), Sienne a contribué significativement à la diffusion et au développement du genre dans le royaume de Naples. L'article signale les voies qui ont pu favoriser ce rayonnement en fonction d'aspects textuels (caractéristiques performatives et dramatisation des modèles) et extratextuels (intervention d'agents diffuseurs : académies, troupes d'amateurs ou "pre-rozzi», imprimerie). Il se conclut sur l'analyse de Il Vendemmiatore de Tansillo.

Mots-clés: églogue, cour, académies, performance, imprimerie, Tansillo.

En el origen de la égloga en vulgar (segunda mitad del siglo XV), Siena contribuyó de manera significativa en la penetración y desarrollo de este género en el Reino de Nápoles. Se esbozan las posibles vías que lo posibilitaron atendiendo a aspectos textuales (características performativas y dramatización de los modelos) y extratextuales (intervención de agentes difusores como academias, compañías de aficionados o "prerozzi» e imprenta). Se concluye con el análisis de Il Vendemmiatore de Tansillo.

Palabras clave: égloga, corte, academias, performance, imprenta, Tansillo.

At the origin of the eclogue in common language (second half of the fifteenth century), Siena significantly contributed to the insight and development of this genre in the Kingdom of Naples. This article outlines possible ways that enabled to take into account textual aspects (performative characteristics and dramatization of the models) and extra-textual (intervention of diffusion agents such as academies, amateur dramatics or "pre-rozzi» and printing). It concludes with the analysis of $I l$ Vendemmiatore by Tansillo.

Keywords: eglogue, court, academies, performance, printing, Tansillo. 
L a égloga en vulgar, cuyas raíces se establecen en Italia durante la segunda mitad del XV, asimila y reinterpreta el bucolismo grecolatino además de los modelos de la tradición medieval (Dante, Boccaccio y Petrarca), para culminar en el siglo siguiente convirtiéndose en un fenómeno de alcance europeo ${ }^{1}$. A lo largo de este arco cronológico, donde la Arcadia de Sannazaro, como afirma De Robertis, representa «ilmomento di massima espansione del genere e insieme alla sua presa di coscienza» ${ }^{2}$, la égloga en vulgar fue cimentando su estatuto de existencia para ofrecerse como un género capaz de acoger diferentes contenidos y definir sus propios rasgos estilísticos a través de un permanente experimentalismo, con su consiguiente enriquecimiento y variedad de resultados. Se trata de un proceso complejo que, a partir de $1460-70$ va dilatándose desde Toscana por el norte y sur de Italia, pone en evidencia la fiebre bucólica que recorrerá todo el Renacimiento, mientras adquiere, según señalaba M. Corti ${ }^{3}$, la fisionomía de una corriente literaria, y que podría definirse incluso como una nueva sensibilidad; es decir, como un fenómeno de entretenimiento o de «civil conversatione», según avance el siglo XVI. Este nuevo bucolismo transitará en diferentes vestiduras formales, tanto métricas como en prosa, e incluye, en esta última modalidad, los prólogos o dedicatorias, que en ocasiones funcionan como verdaderos y sintéticos tratados bucólicos. La égloga vulgar se nutrirá de todo ello y, al mismo tiempo, activará aspectos de su propia y primitiva esencia, como la música, el canto o la danza, que, junto a su estructura dialógica, le permitirá convertirse en un género espectacular e incurrir, por tanto, en el territorio de la dramaturgia ${ }^{4}$.

Resulta sobradamente reconocido el protagonismo de Siena y Florencia como potenciales centros o núcleos de experimentación, cultivo y contribución al desarrollo de la égloga vulgar. El análisis de los testimonios textuales con aportaciones de inexcusable referencialidad (Carrara, Corti, De Robertis, más una larga nómina), así lo certifican, diferenciando básicamente dos trayectorias: la florentina, áulica o cortesana, y la sienesa, realista o «rusticale». Pero quizás estas dos vías no sean suficientes para explicar el alcance de este género dentro y fuera de las fronteras itálicas. Hay aspectos extratextuales que deben ser específicamente atendidos con igual profundidad, pues en muchas ocasiones explican o, cuando menos, contribuyen a dar mayor sentido al éxito logrado por la égloga vulgar. Me refiero a la forma de transmisión/circulación de los textos, oral o escrita, en sus dos modalidades, manuscrita o impresa. Ello implica atender al sector editorial/comercial, que incluye la actividad de los centros productores, la tipología de sus diferentes agentes (libreros, editores, tipógrafos, locales o itinerantes y ambulantes...) o los formatos en que la

1. Cf. Marzia Pieri, «La pastorale», en Manuale di Letteratura Italiana. Storia per generi e problemi: Dal Cinquecento al Settecento, Torino, Bollati-Boringhieri, 1994, t. II, pp. 273-292.

2. Domenico De Robertis, «L'ecloga volgare come segno di contraddizione», en Metrica, Milano-Napoli, Riccardo Ricciardi Editore, 1981, t. II, p. 62.

3. Maria Corti, Nuovi metodi e fantasmi, Firenze, Feltrinelli, 2001, p. 287.

4. Sobre este aspecto remito al trabajo de Marzia Pieri, La scena boschereccia nel Rinascimento Italiano, Padova, Liviana Editrice, 1983. 
égloga se difundió, indicadores significativos, por otra parte, para medir el éxito de la misma. Un cuadro, pues, que se completaría con la movilidad de los autores, determinada por razones no solo culturales sino políticas, más los focos culturales-institucionales y sus dirigentes que propiciaron su difusión. En suma, un reticulado donde todos estos elementos, textuales (estudios singulares sobre autores y textos con los que hasta hoy se cuenta), y extratextuales, queden cohesionados e interrelacionados.

En la deseable configuración del panorama propuesto, del que este trabajo constituye solo un tímido apunte, es inevitable recorrer los aspectos más significativos ya seńalados por la crítica italiana y retrotraerse a ese arco cronológico comprendido entre 1460-90, donde se fijan, según se ha indicado, los cimientos de la andadura de la égloga bucólica en vulgar. Los estudios sobre la paradigmática edición de Antonio di Bartolomeo Miscomini, las Bucoliche Elengantissime, que ve la luz en Florencia en 1482, han centrado tradicionalmente y de forma mayoritaria su atención en el foco de los poetas florentinos en ella compendiados, así como en el contexto cultural que animó dicha edición. Sin embargo, y aun reconociendo en Siena el epicentro del movimiento bucólico "rústico»" ${ }^{5}$, y en definitiva, la génesis del nuevo registro bucólico ${ }^{6}$ que ha fructificado en las diferentes ediciones de los poetas sieneses $^{7}$ y en los numerosos estudios sobre otros autores locales, faltan análisis complementarios que atiendan al contexto y protagonismo cultural de Siena desde la segunda mitad del XV hasta 1557, año en que fue definitivamente anexionada a la signoria medicea. El ensombrecimiento respecto a Florencia responde probablemente al mayor protagonismo de esta, no solo cultural sino sobre todo político, ahogando el de Siena, su secular enemiga. Hasta esa fecha Siena había gozado de un patente esplendor intelectual. Su universidad, ya desde el siglo XIV, representó un importante centro de irradiación humanista donde ejercieron su magisterio figuras que, como Filelfo, gozaban de renombrado prestigio. Su fama había atraído a numerosos estudiantes nacionales y extranjeros, cuya actividad fuera de las aulas contribuyó en parte a la difusión del fenómeno egloguista, conformándose en este sentido un nexo significativo con la de sus múltiples academias, evocadas retrospectivamente por Scipione Bargagli en Delle lodi delle Accademie (1569). Estas academias, que fueron numerosas, y, en especial, la de los Intronati y su predecesora, la Academia Grande ${ }^{8}$, incentivaron una intercomunicación con otros intelectuales foráneos, entre ellos napolitanos, integrándolos como miembros de sus filas.

5. Enrico Carrara, La poesia pastorale, Milano, Casa Editrice Dottor Francesco Vallardi, 1909.

6. M. Corti, Nuovi metodi e fantasmi, op. cit., p. 343.

7. Filenio Gallo, Rime, ed. Antonella Grignani, Firenze, Leo Olschki, 1973; Francesco Arzocchi, Egloghe, ed. Serena Fornasiero, Bologna, Commissione per i testi di lingua, 1995; Jacopo Fiorino de' Buoninsegni, Bucoliche, ed. Irene Tani, Siena, Edizioni ETS, 2012. Citaré en adelante a partir de estas ediciones.

8. Léo Kosuta, «L'Académie siennoise: une académie oubliée du XVI ${ }^{e}$ siècle», Bullettino Senese di Storia Patria, vol. 87, 1980, pp. 123-156. 
Más tarde, la de los Rozzi, reconocida en 1531, desempeñaría, por su parte, un significativo papel en esa línea «rusticale» o realista, así como en la égloga vulgar teatral, no solo por su prolífica producción sino por la itinerancia de sus autores y la interferencia en los contextos aúlico-académicos. Sobre estos pilares, sucintamente señalados aquí, se asienta la capacidad difusora de Siena respecto a la nueva égloga, sin olvidar tampoco, según se anticipó líneas atrás, el papel en todo ello de la actividad tipográfica que, aunque modesta, no sería menos relevante.

Por otro lado, el factor político supuso una condición basilar en este entramado cultural. Mucho más estrechas fueron las relaciones entre Nápoles y Siena, que de estas dos ciudades con respecto a Florencia. Durante el reinado de la dinastía aragonesa, la República encontraría en esta una aliada frente a la permanente pérdida de libertad con la que Florencia amenazaba. El duque Alfonso de Calabria, de marcadas inquietudes intelectuales, desempeñaría un significativo papel, pues bajo una aparente protección política, escondía la pretensión de anexionar Siena a la corona napolitana aprovechando la inestabilidad de la República, continuamente lacerada por la lucha interna de sus facciones. Esto explica en parte esa trashumancia forzada de sus intelectuales, quienes recalaron en el Reino de Nápoles en busca, probablemente, de un mecenazgo que su ciudad era incapaz de proporcionarles. La corte aragonesa constituía por aquel entonces uno de los centros culturales de mayor esplendor y atracción para humanistas y poetas, a los que se acogía al amparo de una cortesanía pródiga en festejos, representaciones dramáticas, músicas y bailes. Pero era sobre todo su vinculación con la Academia Pontaniana y el reconocido prestigio de sus miembros, el foco de mayor interés para esos poetas sieneses que importaron como innovación la práctica de esa égloga en vulgar en la que, ya desde hacía tiempo, se venían ejercitando. Desde los años ' 30 del siglo siguiente, la política imperial de Carlos V vino a intensificar estos lazos: el Reino de Nápoles y la República de Siena formaron parte de sus dominios y de su estrategia político-militar, favoreciendo paralelamente las relaciones culturales.

Regresemos ahora al valor paradigmático de la antología Miscomini, posteriormente reeditada en 1494 , en cuyo corpus se recogen un puñado de églogas de autoría sienesa: las de Francesco Arzocchi y de Jacopo Fiorino di Buoninsegni. Desde el punto de vista literario, las Bucoliche elegantissime son el resultado de unas experimentaciones lingüísticas de traslación al toscano de las églogas virgilianas y teocriteas (de estilo «humile» y «mediocre»), en las que se venía ejercitando esa «cerchia» o academia «dei buccoici», según explica Bernardo Pulci en el prefacio, para marcar el estado de la cuestión de la égloga vulgar hasta esa fecha. Tras el aparente y culto «divertissement» se encubre, como ya destacó Battera', una intencionalidad política para reforzar, tras la Conjuración de los Pazzi (1478), la debilitada figura de Lorenzo de’ Medici.

9. Francesca Battera, «L'edizione Miscomini (1482) delle Bucoliche elegantissimamente composte», Studi e Problemi di Critica Testuale, vol. 40, 1990, pp. 149-185. 
Así, exceptuando las cuatro églogas de Arzocchi, las restantes antologadas revisten un carácter encomiástico, como resulta evidente en la "Epistola mandata al Magnifico Laurentio de Medici», fechada el 24 de diciembre de 1581, pocos meses antes de que saliera a la luz la Miscomini, al «tempo de la invittissima sua ribellione dalla patria» (22 junio de 1480), precediendo a la última de las cinco églogas de Buoninsegni «Foelicità pastorale», "picciola fatica et primitia del mio exilio». Diferencia de esta manera el autor esta de sus restantes cuatro, de "più basso stile», que conforman el grupo dedicado al duque de Calabria. Poco antes se había firmado la paz entre Florencia y Nápoles (publicada en Siena el 25 de marzo de 1480), pero también en ese año el duque de Calabria, tras haber residido e intervenido en el gobierno de la república sienesa, apoyando la facción de los Riformatori, a la que pertenecía Buoninsegni, había abandonado la ciudad y regresado a Nápoles ante la amenaza de los turcos, que hostigaban Otranto. Buoninsegni era uno de los expulsados de esa Siena que se vengaba de los Riformatori al sospechar de una posible alianza con el duque para su anexión a la corona aragonesa. Por ello, en el prefacio a sus cuatro églogas, se confiesa "già buon tempo incognito servo". Fuera estrategia política o no, lo cierto es que la edición primera de Miscomini dio a conocer, gracias a la utilización no menos estratégica de la imprenta, esos primeros testimonios de la experimentación bucólica de raíz sienesa. Porque, si en Florencia se "bucoleggiava», como decía E. Carrara, no menos sucedía en Siena, que se daba a nuevos experimentalismos, según demuestran las cuatro églogas de Arzocchi compuestas en una lejana cronología, quizás antes de 1440, cuando este rondaba, según Fornasiero, los sesenta años; época, además, en que Arzocchi era ya un reconocido exponente del bucolismo en vulgar, modelo para otros autores del ámbito sienés (Musca, Suardi...) ${ }^{10}$, sin excluir al propio Buoninsegni. Particular admiración fue la de Luigi Pulci, a cuya mano parece deberse la transcripción de las mismas églogas en un códice de la Biblioteca Palatina de Parma, como aporta también Fornasiero ${ }^{11}$. De este puñado de églogas, la primera, "Dimmi, Terinto, che hai zampogna e cetera", se ofrece pionera de la égloga vulgar por cuanto significa un distanciamiento respecto al bucolismo clasicista mediante el uso de un lenguaje realista teńido de rasgos locales, de la práctica de versos esdrújulos, del intercalado de la frottola como artificio (primacía que Carrara reconoció en Arzocchi frente a Giusto de' Conti) o de la introducción del canto y la danza coral, que, combinados en la estructura dialógica, posibilitarán futuras realizaciones dramáticas. Dicho experimentalismo se dilata también en sus restantes églogas: en la segunda ("Ora de' monti, ogni ombra s’e partita»), donde inserta una especie de acertijo o juego técnico para designar el nombre de la ninfa amada, en consonancia con una moda muy extendida en la época y tratada por L. B. Alberti en De componendi cifris, según E. Carrara, y en la tercera («Seguendo l’orme d’un

10. Sobre Giorgio Musca, véase Renzo Rabboni, «Per Giorgio Musca e per l'egloga volgare», Studi e Problemi di Critica Testuale, vol. 54, abril 1997, pp. 45-66.

11. Serena Fornasiero, Francesco Arzocchi, Egloghe, op. cit., p. LXV. 
bramoso capro»), salpicada de onomatopeyas venatorias ("Piglia Paluffa, buffa, nella zuffa» v. 29 y vv. 42-3) que volveremos a encontrar en otros autores, entre los cuales, el napolitano Jacopo de Jennaro. Pero del valor emblemático de la primera y de su proyección en el contexto literario partenopeo da cuenta un códice manuscrito misceláneo de finales del XV (Rime ed alcune prose d'autori napoletani), objeto de varios análisis de diferentes estudiosos donde convive ${ }^{12}$, adaptada al dialecto napolitano, con otras composiciones hispánicas, y aparece, significativamente, con una farsa de Sannazaro, la égloga V de De Jennaro y otras composiciones eglógicas pertenecientes a Galeota y Caracciolo.

Esta asimilación napolitana de la égloga arzocchiana se encuadra, como vemos, en ese contexto académico-cortesano, y de ella probablemente sería luego deudor Garcilaso, con su práctica ya madura de la rima al mezzo en la égloga II. La penetración del experimentalismo bucólico en vulgar de poetas sieneses en el área napolitana de finales del XV, sin descartar que sus producciones circularan manuscritas, se estableció fundamentalmente a través de los contactos directos con los miembros de los círculos académicos pontanianos, donde se concitaban los ya mencionados poetas cortesanos junto a otros procedentes de otras latitudes itálicas (Perleoni, Aquilano...). Cabe también sumar figuras políticas como la del duque de Calabria, relevante nexo por su relación con Siena, según se ha visto a propósito de Buoninsegni. Y aunque en muchos casos los datos biográficos de los poetas sieneses resultan muy escasos, los testimonios literarios dan indicios de posibles contactos directos o, al menos, de conocimiento de sus rimas por parte de los napolitanos. Así, por ejemplo, en el cancionero del partenopeo Jacopo de Jennaro figura un soneto dedicado al sienés Jacopo Tolomei ${ }^{13}$, que principia «Le dotte rime toi languide e conte [...] amo leggendo", cuyo epígrafe lo ratifica ${ }^{14}:$ "Al magnifico messer Jacopo Tolomeo, avendo lette certe rime per lui fatte».

Jacopo De Jennaro, la figura poética rescatada por M. Corti de la errónea asignación, por parte de E. Percopo, como imitador de la Arcadia de Sannazaro, representa un evidente testimonio de conexión personal entre determinados poetas del innovador bucolismo sienés y los círculos napolitanos. Y, en concreto, de una figura como el fraile agustino Filippo Gallo de Monticiano, según acredita la Pastorale del napolitano ${ }^{15}$, dedicada precisamente al duque de Calabria. Una amistad de ámbito cortesano que se forjaría en Venecia y en Ferrara para afianzarse asimismo en la posible estancia del agustino en Nápoles, según reflejan tres sonetos recogidos en el cancionero del también poeta áulico Giuliano Perleoni o Rustico Romano (Compendio di Sonecti et altre Rime

12. Ibid., p. LXVII.

13. Se deben a Carlo Dionisotti los datos que se conocen de este poeta. Cf. Dionisotti, «Jacopo Tolomei fra umanisti e rimatori», Italia Medievale e Umanistica, no VI, 1963, pp. 137 176.

14. Es el 103 en Pietro Jacopo de Jennaro, Rime e Lettere, ed. Maria Corti, Bologna, Commissione per i testi di lingua, 1956, p. 137.

15. Cito por Erasmo Pércopo, La prima imitazione dell'Arcadia: aggiuntevi l'Egloghe pastorali di P.J. De Jennaro e di Filenio Gallo ecc, Napoli, Tipografia della Regia Università, 1894. 
de varie texture, intitulato lo Perleone, Nápoles, 1492), quien, procedente de Roma, se asentó en Nápoles por aquellas fechas. Se trata de «Dimmi Phyleno mio che Nimpha è questa», "Phyleno, il viso tuo pallido e mesto» $\mathrm{y}$ "Philenio mio, tempo è che techo ormai» $(1491)^{16}$. Asimismo, en este misceláneo cancionero, entre la nómina de personajes interlocutores-amigos (De Jennaro, Galeota, Caracciolo) se menciona también al propio Filenio ${ }^{17}$. Pero también, entre otras composiciones de autoría propia, figura una de carácter encomiástico, la "Canzone $V$ de nuova textura», dedicada al duque de Calabria, que el autor, disfrazado de pastor, había recitado en un banquete con ocasión del regreso de su señor, victorioso tras la campaña de Otranto. Nos situamos, por tanto, a finales del XV, ante un ambiente cortesano donde el nuevo código pastoril o la nueva égloga vulgar de raíz sienesa se impone y se perfila como una de las formas favoritas de comunicación literaria, que va a irse adecuando a las exigencias del espectáculo cortesano napolitano con motivo de banquetes, celebraciones o simples entretenimientos en los que el autor es también actor ${ }^{18}$. En suma, un contexto perfecto para convertir la égloga en una dramatización enriquecida, además, por la música y el baile ${ }^{19}$. De ahí que las églogas de Filenio Gallo, Safira y Lilia (escritas quizás hacia 1470), de emblemática circulación en este contexto áulico y como continuidad de esa línea innovadora que proponía ya la primera égloga de Arzocchi, recojan sus mismos presupuestos formales (versos esdrújulos, expresividad local e incorporación de canciones, frottole y estrambotes) y apunten hacia un vitalismo de la égloga vulgar de praxis no exclusivamente lectora, individual o silenciosa, sino con voluntad de exteriorización y de apertura hacia una fruición pública o colectiva ${ }^{20}$. No obstante, el soneto que cierra Safira señala destinación a la lectura «Ad lectores aegloghae», lo que permite deducir la doble fruición del género: leída o representada. $\mathrm{Y}$ en efecto, las posibilidades dramáticas de su estructura dialógica, así como de la introducción de canciones y estrambotes entonados,

16. Pércopo reproduce los dos últimos, mientras M. Corti añade el tercero recogido en su Canzoniere, en Nuovi metodi e fantasmi, op. cit. p. 356.

17. Cristiana Anna Addesso, «Un pastore "cortigiano" su un "sentiero angusto et solitario". I testi bucolici del canzoniere di Giuliano Perleoni detto Rustico Romano (1492)», en Daria Perocco (ed.), Tra boschi e marine. Varietà della pastorale nel Rinascimento e nell'Età barocca, Bologna, CLUEB, 2012, pp. 42-62, y M. Corti, Nuovi metodi e fantasmi, op. cit., demuestra cómo la égloga IV de De Jennaro es un collage sobre temas procedentes de la Safira de Gallo.

18. Véase Francesca Bortoletti, «Arcadia, festa e performance alla corte dei re d'Aragona (1442-1503)», The Italianist, vol. 36, no 1, febrero 2016, pp. 1-28, donde analiza la Arcadia en clave de poesía oral y para recitar en el ámbito de la dramaturgia teatral y de la fiesta cortesana.

19. Marzia Pieri, «Dalla lirica alla festa: il caso dell'egloga a Napoli aragonese», en M. Chiabò y F. Doglio (eds.), Origini del dramma pastorale in Europa. Atti del convegno del Centro di studi sul teatro medioevale e rinascimentale di Viterbo, Viterbo, Union Printing, 1985, pp. 71-89.

20. Según Francesco Luisi, el fenómeno de la frottola está vinculado a la actividad de los Rozzi, una academia de la que nos ocuparemos más adelante; véase «La frottola nelle rappresentazioni popolaresche coeve», en A. Pompilio, L. Bianconi, D. Restani, F. Alberto Gallo (eds.), Atti del XIV Congresso della Società Internazionale di Musicologia. Trasmissione e recezione delle forme di cultura musicale: Study sessions, Torino, EDT, 1990, t. II, p. 232. 
se materializan años después, en 1524, cuando Safira se convierte en una pieza teatral difundida en un librillo en $4^{\circ}$, de 12 páginas y de frontispicio ornamentado, con el título de «Eglogha pastorica a sdrucciolo di Phyleno Gallo da Monticiano", impresa en Siena, "p.M.di B.F. Ad instantia di m.G.di.A.L. a di 30 Luglio» $^{21}$.

El prólogo de Safira, por otra parte, constituye un verdadero compendio de los topoi bucólicos, que el autor desgrana insertándolos en ese contexto cortesano o, cuando menos, elegante, para destacar precisamente el valor canoro, rústico, que apela a esa nueva sensibilidad bucólica, reflejo, como se señaló al principio, de una moda social. Y así lo justifica mediante la fórmula retórica "più... che»:

Per la viariabilità de li insaziabili appetiti umani [...] che per l'abondanzia e continuo possesso di una cosa [...], infastiditi, altre dissimili e a quelle inferiori appetiscano. Ricordomi spesso aver da persone di stima inteso dire piu alle volte esserli aggradato sopra verdi ed odorifere erbete, a l'ombra di fronduti arbuscelli [...] più nel grosso suono di sampogne e suffili e fastidioso gracellare de le pastorali pive e de' bifolchile citere, che ne le misurate armonie de' gavicordi e liuti, ne le dipinte camere delettarsi.

En esta línea de refinamiento cortesano, se expresará Sannazaro, con evidente proximidad, en el prólogo a la Arcadia, para igualmente señalar, desde sus «rozze egloghe» y su vinculación a la música, la penetración y confluencia de dos mundos tan antagónicos, el de la «rusticitas» y el cortesano y elegante que precisamente permite la égloga: «Sogliono i più delle volte [...] e le incerate canne dépastori porgano per le fiorite valli forse più piacevole suono, che li tersi e pregiati bossi de 'musici per le pompose camere non fanno» ${ }^{22}$.

La vertiente musical de la égloga, nos viene también a decir Gallo en este proemio, discurre paralela a la diferenciación de lenguajes de esta su «rurale e pastorica mia opereta» $\mathrm{o}$ "libreto de versi humili e bassi», donde, bajo «il velame pastorico», narra una "verissima» y "moralizzante» historia amorosa expresada en rima esdrújula (71 tercetos de 100, según contabiliza): el rústico/realista que el autor asigna al pastor Filenio acorde con su condición, y el elegante de la ninfa Safira, docta, bella y púdica. La música no puede sino pertenecer a esa esfera rústica, y sin embargo, al final de la égloga, la ninfa acaba entonando una canzonetta con Filenio. Este hecho puede quizás significar esa convivencia de universos sociales a la que me acabo de referir y en definitiva corroborar cuanto el autor ha manifestado al principio del proemio sobre esas preferencias rústico-pastoriles de la sociedad refinada y cortesana a la que se está dirigiendo. El repertorio musical en Safira se conforma, además de con la canzonetta, con la frottola (v. 590) y los estrambotes, completando así la preceptiva de ese nuevo universo eglógico que lo convierte en escenificable. Asimismo, Lilia se remata con una canción entonada por los dos pastores Filenio, Silverio, además

21. Esta impresión fue ya dada a conocer por E. Pércopo. El ejemplar que manejo está depositado en la Biblioteca Comunale de Siena, sign. 128 VII R.

22. Sannazaro, Arcadia. Opere volgari, ed. Alfredo Mauro, Bari, Laterza, 1961, "Prologo», p. 3. 
de la ninfa. La Safira, de la que debemos recordar en esta línea su inserción de estribillos, constituye pues una summa o codificación sintetizada de la égloga vulgar, y junto a Lilia se convirtieron ambas en un referente modélico del que no hay que olvidar su doble circulación manuscrita e impresa (1524 y 1528 , respectivamente). En este sentido y en esta vertiente espectacular, no es descartable una posible y posterior lectura de ambas por parte de Luigi Tansillo, que inspirarán $I$ due pellegrini, definida por la crítica como égloga dramática. A propósito de Lilia, G. Carducci quiso ver cierta influencia en esta obra tansilliana, escrita en 1527 y representada, como es sabido, el 26 de diciembre de 1538, en Messina, durante la fiesta organizada por don García de Toledo en honor de dońa Antonia de Cardona ${ }^{23}$. Un acontecimiento cuyas particularidades se conocen gracias a la descripción del propio Tansillo en su Discorso di Luigi Tansillo sopra la Collana d'oro (106 ${ }^{24}$. Ampliando el radio de influencia de esta misma égloga, Carducci la proponía también como modelo de la Cecaria de Epicuro, representada en 1523 y editada en Venecia en 1525, tesis que será corroborada por la crítica (por ejemplo, Francesco Flamini) al señalarla como referente directo e inspirador de I due pellegrini $i^{25}$. La coincidencia temática en la que se suele basar la dependencia entre esta obra de Epicuro y la égloga tansilliana -es decir, la evitación del suicidio por amor a cargo de una pastora o ninfa que sella el final feliz, común a las dos églogas de Gallo, y que alcanza también a Garcilaso en su égloga II- responde, sin embargo, a una larga tradición remontable a la égloga VIII de Virgilio, recogida, según advierte L. Riccò ${ }^{26}$, por la Miscomini en la traducción de las églogas virgilianas y en la recreación del florentino Girolamo Benivieni. Probablemente, el tópico llegara a Epicuro desde las fuentes de Safira y Lilia en esa misma línea moralizante que desprenden ambas églogas y que confiesa además el propio Gallo en el citado proemio. Para Cecaria, por otra parte, E. Giorgi sugirió un eco de la égloga de Buoninsegni Ganimede morto ${ }^{27}$, por cierto, acento religioso o sacro, dado que el rescate, en el texto de Epicuro, corre a cargo de un sacerdote, lo que la vincularía con el filón de églogas sagradas que ya existía en Siena ${ }^{28}$. En Siena, además, el tópico del suicidio por amor se evitará también por los "pre-rozzi", como en la égloga dramatizada de Niccolò Campani, Il coltellino. Creo que la intervención salvadora de una ninfa en I Due Pellegrini está más cerca de los

23. Giosuè Carducci, Su l'Aminta di Torquato Tasso. Saggi tre, Firenze, Sansoni, 1896, p. 34.

24. Luigi Tansillo, Rime, ed., introd. y notas Tobia Toscano, Erika Milburn y Rossano Petarino, Roma, Bulzoni Editore, 2011, t. I, p. 487.

25. Giosuè Carducci, op. cit., y Francesco Flamini, L'egloga e i poemetti di Luigi Tansillo secondo la genuina lezione dei codici e delle prime stampe con introduzione e note di Francesco Flamini, Napoli, per i tipi del Cav. V. Vecchi, 1893. A propósito de su comentario sobre I due pellegrini, son frecuentes sus anotaciones sobre la dependencia de la Cecaria de Epicuro.

26. Laura Riccò, Dalla zampogna all'aurea cetra. Egloghe pastorali, favole in musica, Roma, Bulzoni, 2015, pp. 20-21.

27. Emilio Giorgi, «Le più antiche egloghe volgari», Giornale storico della letteratura italiana, vol. LXVI, 1915, p. 150.

28. Es tesis corroborada hace algunos años por Stefano Carrai en La lirica di corte nell'Italia del Quattrocento, Milano, Franco Angeli, 1993, pp. 137-9. 
dos modelos de Gallo, pues se trata de una salvación profana común a ambos. Y, por otra parte, quizás también otro vínculo de la Safira con la égloga de Tansillo pueda establecerse en esa diferenciación de naturalezas, ya explicitada antes, entre el rudo pastor Filenio y la ninfa: Alcinio procede de un «humil tetto», mientras la ninfa es "leggiadra e bella assai più che pudica», calificación, esta última, presente en el texto arriba señalado de Safira.

Tras este inciso y regresando a la frottola como canto paradigmático del nuevo bucolismo en vulgar, es también observable la presencia de la rima frottolel grottole, que exhiben los vv. 584-6 de Safira, reflejo de esa continuidad de la rima inaugurada por Arzocchi, frottolal nottola (égloga I: «Deh, or dimmi quella pur Come la nottola, / che tu l'altrier cantavi sotto un suvaro! / Terinto -Dunque m’udisti? Or, ella è una frottola»), cuya rentabilidad métrico-esdrújula es evidente, con arrastre de otras variantes en la segunda égloga de De Jennaro ( Sú sú, lieto, sú sú, da quessa grottola»; grottolal frottola) y en Arcadia (égloga I, Ergasto: «...oscure grottole / [...] importune nottole», así como seguramente en otros textos de la época de posible rastreo. Puede tratarse de un indicio relativo a la codificación de la rima esdrújula. La frottola contaba además con una ejercitación en el área toscana, concretamente entre los «buccoici»: un ejemplar de la edición de 1494 de la Miscomini, conservado en la Biblioteca Comunale de Siena (sign. N.V.030), lleva de hecho anexado un cuadernillo que contiene la producción frottolistica de Luigi Pulci, cuyo frontispicio representa a un joven leyendo no ya un libro de banco, sino una hoja suelta sobre un atril o soporte de menores dimensiones, quizás como representación indicativa de que las frottole, además, pertenecían a un género popular, por lo que a su circulación correspondía un formato diferente. Las frottole además, musicadas o no, en el ámbito cortesano napolitano entroncaban perfectamente con las farsas, los estrambotes y los gliommeri (serie de endecasílabos con rima al mezzo con una métrica pareja a la frottola ${ }^{29}$, de exclusiva tradición partenopea y específicamente sannazariana, tradición en la que se engloban también las populares villanelle. No puede olvidarse que los poetas napolitanos de esos finales del XV son poetas, actores, cantores, expertos en música, como Cariteo, Serafino Aquilano ${ }^{30}$, Pier Antonio Caracciolo o Rustico Romano, entre otros. La música representaba un factor de relevancia en cualquier composición lírica o dramática, como ilustra el testimonio de Bernardo Tasso, cuando, ya entrado el siglo XVI, en una carta no fechada dirigida al príncipe de Salerno ${ }^{31}$, al refirirse a unas estancias que acababa de concluir, indicaba su incapacidad para este arte al solicitar que el acompañamiento musical fuera asignado a algún

29. Cf. Nicola De Blasi, «A proposito degli gliommeri dialettali di Sannazaro: ipotesi di una nuova attribuzione», Studi Rinascimentali. Rivista internazionale di letteratura italiana, vol. V, 2007, pp. 56-76, donde desmonta la atribución de G. Parenti del gliommero Eo non agio figli né fittigli a De Jennaro.

30. Véase la edición de Giuseppina La Face Bianconi y Antonio Rossi, Le rime di Serafino Aquilano, Firenze, Leo S. Olschki Editore, 1999, donde se recogen las músicas de 28 estrambotes y un capítulo según fuentes recabadas entre finales del XV y principios del XVI.

31. Le lettere di Bernardo Tasso, vol. I, Venetia, Giovanni de' Picchi \& fratelli, 1578, pp. 160-1. 
músico. En cualquier caso, todo este material de ejecución dramática y musical se integraba, en este contexto napolitano, dentro de las representaciones teatrales, entretenimientos o festejos cortesanos, en los que se implicaban como actores-recitantes o cantantes todos los poetas mencionados, potenciando así la espectacularidad de la égloga ${ }^{32}$. Es precisamente en Nápoles, en la primera mitad del XVI, donde se utilizaron por primera vez y en dos ocasiones, los caracteres móviles musicales. La primera ocasión en Fioretti di frottole barzellette e capitoli strambotti e sonetti. Libro secondo, impresa en Nápoles por Antonio de Caneto a instancias de Premartini en 1519; la segunda, en 1537, en Canzoni villanesche alla napolitana, impreso por Giovanni da Colonia. Pero sería en realidad Mattia Cancer quien daría el definitivo impulso en la segunda mitad del XVI a la edición musical. No obstante, en Siena, aparecía un producto más temprano de esta tipología editorial, con fecha de 1515 (30 de agosto), titulado Canzoni sonetti strambotti et frottole, publicado por Pietro Sambonetto, del que solo se sabe su origen napolitano, según reza el colophon, aunque posiblemente se tratara de un impresor ambulante. El ejemplar completo, hallado en una biblioteca de Cracovia por F. Luisi, lleva en su frontispicio una escena pastoril compuesta por un público femenino (tres damas) y un grupo de faunos músicos que entonan una composición, cuyo texto, representado en forma de libro abierto, es curiosamente el propio ejemplar de Sambonetto ${ }^{33}$. El origen de la edición musical, corrige Luisi, generalmente atribuido a Ottaviano Petrucci di Frossombrone, se debió a Andrea Antico da Montona, cuyas matrices musicales distribuyó por toda Italia: Roma, Venecia y Nápoles. Quizás Sambonetto recalara en Siena aprovechando un contexto favorable de impresiones populares, en un ambiente donde la música y la danza eran un elemento de las escenificaciones de églogas vulgares o de una dramaturgia rústica que iban desarrollando los llamados pre-rozzi y luego los miembros de la Academia de los Rozzi.

Estos, denominados "pre-rozzi» o "comici artigiani», conformaron, desde finales del siglo XV, un circuito oral, rústico, alternativo y paralelo a la actividad culta de los Intronati, potenciando esa línea de difusión de la égloga. Escenificaron, como diversión, sus propias creaciones, consistentes en églogas pastoriles, farsas, "mascherate» o comedias rústicas, disfrazados según el contenido de su variado repertorio ("alla martorella», "alla moresca», como rezan sus títulos) ${ }^{34}$. Se trata de artesanos o pequeño- burgueses, autores/

32. Cf. Francesca Bortoletti, «La voce dei poeti alla corte aragonese. La festa e il teatro», Quaderni d'Italianistica, vol. XXXVI, no 1, 2015, pp. 13-52.

33. Francesco Luisi, «Dal frontespizio al contenuto. Esercizi di ermeneutica e bibliografia a proposito della ritrovata silloge del Sambonetto (Siena, 1515)», en Studi musicali, año XXVIII, no 1, 1999, pp. 61-115.

34. Remito al estudio pormenorizado de Cristina Valenti, Comici artigiani. Mestiere e forme dello spettacolo a Siena nella prima metà del Cinquecento, Modena, Panini, 1992, y también al volumen Commedie rusticali senesi del Cinquecento. Testi e studio linguistico, ed. Bianca Persiani, Siena, Betti Editrice, 2004, donde se analizan críticamente diez comedias rústicas de los prerozzi y Rozzi entre 1511-1550. 
actores con diferentes profesiones identificables en los apelativos con los que dejaron memoria, que hicieron de sus creaciones bucólicas y su representación un entretenimiento y una forma lúdica y ocasional de reflejar la actualidad de su ciudad. Sus espectáculos, realizados con una técnica rudimentaria y un acompańamiento musical al son de la lira o "citarino», además de la danza, solían representarse en ocasiones relacionadas con las fiestas campesinas, con el carnaval o con la visita de algún poderoso ${ }^{35}$. Se trató de un fenómeno esencialmente urbano y, en este sentido, identificable también por la constante sátira contra la rusticidad del campesino, característica de comprensible paralelismo con las farse cavaiole, género cómico teatral, genuinamente napolitano y de gran éxito cuyo objeto era la burla del rústico de la localidad de Cava dei Tirreni ${ }^{36}$. Por otra parte, estos cómicos-artesanos se integraban en compañías y se asociaban en «brigate» o «congreghe», como la de los Rozzi, que, a partir de 1531, se transformará en academia: la Accademia dei Rozzi. Algunos de ellos se desplazaron a otros centros o ciudades, donde exportaron sus productos y donde, por su capacidad artística, alcanzaron grandes éxitos. Es el caso de Mescolino y de Niccolò Campani, alias lo Strascino, quienes recalaron en Roma ${ }^{37}$ y, bajo la protección del mecenas y banquero sienés Agostino Chigi, accedieron a los ambientes cortesanos y a los salones curiales del Papa León $\mathrm{X}^{38}$. En Roma también, donde le sorprenderá la muerte en 1500, Serafino Aquilano había alcanzado una merecida notoriedad como poeta, músico y actor: en 1490, durante el carnaval, fue famosa su recitación de la égloga pastoril "Dimmi Menandro mio, deh, dimmi sozio»" ${ }^{39}$ Y las compañías de los pre-rozzi llegarán también a Nápoles y desarrollarán su actividad paralela a las cortesanas amateurs en torno a Ferrante Sanseverino, integradas por intelectuales como Antonio Muscettola, Luigi Dentice y Antonino Castaldo ${ }^{40}$, quienes en 1542

35. Por ejemplo, Ambrogio Maestrelli, alias Mescolino, según señaló Marzia Pieri, recitó disfrazado de pastor unas estancias ante Carlos de Lannoy, a la sazón virrey de Nápoles, durante su visita a Siena; véase Marzia Pieri, «Mescolino Maggiaolo: fra il contado di Siena e la Farnesina», en Francesca Bortoletti (ed.), L'attore del Parnaso. Profili di attori-musici e drammaturgie d'occasione, Milano, Mimesis Edizioni, 2012, p. 384.

36. Entre las farsas de este tipo que han pervivido, cabe mencionar la Farsa dellimperatore alla Cava, donde precisamente se recrea el episodio cómico sucedido con motivo de la fallida visita de Carlos V a esa localidad. Cf. Francesco Senatore, La ricevuta dellimperatore alla Cava, Napoli, Dante \& Descartes, 2012, pp. 5-13.

37. A estos dos pre-rozzi ha dedicado dos interesantes trabajos Marzia Pieri. Respecto a Mescolino, cf. «Mescolino Maggiaolo: fra il contado e La Farnesina», op. cit. pp. 381-417, y la edición Lo Strascino da Siena e la sua opera poetica e teatrale, Pisa, Edizioni ETS, 2010.

38. Sobre los espectáculos en la curia de León X y la relación con los pre-rozzi, véase Curzio Mazzi, La Congrega dei Rozzi di Siena nel secolo XVI, Ristampa anastatica, Siena, Betti Editrice, 2001, vols. I y II.

39. Sobre esta faceta de músico-poeta y su maestría performativa, véase F. Bortoletti, Egloga e spettacolo nel primo Cinquecento. Da Firenze alle corti, Roma, Bulzoni Editore, 2008, pp. 183218.

40. Dell'historia di Notar Antonino Castaldo. Libri Quattro nei quali si descrivono gli avvenimenti più memorabili nel regno del Viceré D. Pietro di Toledo e dé viceré suoi successori fino al Cardinal Granvela, Napoli, Giovanni Gravier, 1769. En pp. 71-2 se describe este espectáculo 
pondrán en escena Gli Ingannati, comedia de los académicos Intronati. Tal acontecimiento no es fortuito, pues se explica desde ese otro circuito culto y de relaciones culturales entre Siena y Nápoles que se intensificará en los cuatro años siguientes a través de la mencionada Academia de los Intronati, a la que, desde 1525, pertenecían estos personajes: Antonio Muscettola (l'Inquieto), el músico aristócrata Luigi Dentice (Il Rispettoso), junto a personalidades políticas como el duque de Amalfi (Il Desiato), además del marqués del Vasto (Il Pomposo) y el propio príncipe de Salerno (L'Ostinato ${ }^{41}$.

La difusión de las creaciones de los pre-rozzi y de los Rozzi académicos no se explica sin el sentido comercial de estos autores y sin el auxilio de la imprenta, que intensifica su difusión. Siena era un centro productor de impresiones populares, si bien al principio de la imprenta escasearon las tipografías debido a la sólida resistencia del libro manuscrito. Sin embargo, desde finales del XV, en la ciudad existían tiendas de artesanos, exponentes de una industria editorial local que durará hasta finales del XVI y que emitía productos vendibles, de pequeño formato y bajo coste, preferentemente de contenidos populares, entre ellos las églogas, con su gran variedad temática. Solían definirse como tipógrafos, libreros, editores, calcógrafos o papeleros, y su actividad estuvo muy vinculada también a las instituciones locales: las academias y la universidad ${ }^{42}$, pues imprimían no solo las producciones de sus miembros, sino también de los estudiantes. Los libreros, en especial, supieron colocar estos productos en una red comercial, lo que explica su difusión por todo el territorio itálico. Nombres como los de Francesco de Simione, Simone di Niccolò Nardi, Francesco Nardi y, en especial, del prolífico Giovanni Landi, bedel del Studio, conocido como "Giovanni delle commedie», han pervivido gracias a dichos impresos, que permiten reconstruir la interesante producción egloguista de este medio en toda su amplia variedad ${ }^{43}$. A esta nómina de impresores locales hay que sumar los itinerantes, que se instalan temporalmente en Siena. Su movilidad por toda la geografía italiana respondía a la necesidad de hallar oportunidades laborales. En 1535, por ejemplo, Luca Bini, se asocia en Siena con Niccolò Nardi, hijo de Simone Nardi, y Antonio Mazzocchi inicia ahí su andadura imprimiendo

como ejercitación cortesana y entretenimiento de la ciudad de Nápoles y con gran aparato de luces, música y disfraces.

41. Luigi Sbaragli, «I "Tabelloni” degli Intronati», Bullettino Senese di Storia Patria, vol. 49, 1942, p. 191.

42. Véase Lodovico Zdekauer, Lo Studio di Siena nel Rinascimento, Milano, Hoepli, 1894. En esta universidad había estudiado leyes el Panormita.

43. Nicola Pallecchi, "Nota su Simone Nardi e sul commercio di edizioni senesi», en Le fusa del gatto. Libri, librai e molto altro, Società Bibliografica Toscana, 2014, pp. 91-100. Del mismo autor, cf. «Una tipografia a Siena nel 16 secolo: bibliografía delle edizioni stampate di Simone di Niccolò Nardi (1502-1539)», Bollettino Senese di Storia Patria, vol. 109, 2002, pp. 185-233. Y sobre todo, M. De Gregorio, "Ad istantia di Giovanni d'Alessandro libraro”. Percorsi editoriali a Siena nel primo Cinquecento», en Gabriele Borghini, Daniele Danesi, Mario De Gregorio, Luigi Di Corato (eds.), Siena bibliofila. Collezionismo librario a Siena su Siena, Protagon Editori, Siena, 2009, pp. 29-41. También el artículo pionero de Francesco Iacometti, «Il primo stampatore senese Simone di Niccoló di Nardo", La Diana, año I, no 3, 1926, pp. 186-9. 
églogas y cierta producción del «cantastorie» Giovanni Sacco. Y así una larga nómina a la que se añade la actividad de los impresores ambulantes, como posiblemente lo fue el salernitano Francesco Fabri. En Nápoles, la actividad editorial e impresora fue muy diferente, pues estuvo muy vinculada durante la dinastía aragonesa a la esfera política y a la Academia Pontaniana, de modo que impresores como Sigismondo Mayr, Giovanni De Caneto o Pasquet De Sallo se dedicaron a imprimir muy a principios del XVI las obras de sus miembros, como las del propio Sannazaro, Caracciolo, Cariteo, Pontano o de De Jennaro, para luego, entre 1526-29, decaer por diferentes motivos políticos y estrecho control de las autoridades. Como explica Pietro Manzi ${ }^{44}$, en este panorama áulico de público restringido, se justifica la escasez de impresiones populares, y en cuanto a la égloga, sus publicaciones se limitaron generalmente a las creaciones de ejercitación cortesana de los gentileshombres napolitanos, recogidas en ediciones misceláneas. Un ejemplo es el volumen del impresor Sigismondo Mayr, asentado desde principios del XVI en la ciudad partenopea, Egloghe di gentiluomini napoletani della fine del secolo $X V$, fechado el 26 de enero de 1503.

Posiblemente las impresiones sienesas de églogas rústicas ${ }^{45}$ o de este tipo de productos, como «mascherate» o farsas, suplieron esa laguna del mundo editorial napolitano al penetrar en el circuito cortesano, como ocurría en Siena, donde el académico y culto de los Intronati admitía en ocasiones la intercalación en sus representaciones dramáticas de ciertas églogas pastoriles de los Rozzi. Era una forma distensiva y de entretenimiento para contrastar con el tono áulico academicista, consonante con la elegancia de las reuniones gentilicias y privadas que paralelamente se celebraban en la ciudad. Una de estas líneas cultivadas fue la erótica, a la que fue también sensible la égloga en vulgar en sus diferentes formas de espectáculo. Se trataba de una vertiente en que la relación del mundo de los pastores y el agreste se sostuvo sobre la asimilación y selección de modelos grecolatinos como Teócrito (idilio XX, v. 33), los Sermones de Horacio, los levia carmina de Polión, las églogas de Nemesiano o los poetas del círculo catuliano. Una vena que a su vez llevaba asimilada la corriente dionisíaca en su doble valencia de manifestación desenfrenada de los instintos, expresada en himnos y cortejos de exaltación al dios del vino, Baco, protector de la vida de los campos, como demuestran las Geórgicas virgilianas, por cuanto atendían a la preparación de las tierras y al cultivo de la vid, así como a la recolección de su fruto ${ }^{46}$. De ahí también el

44. Pietro Manzi, La tipografia napoletana nel '500 (1503-1535). Annali di Sigismondo Mayr. Giovanni A. de Caneto. Antonio de Frizis. Giovanni Pasquet de Sallo, Firenze, Leo Olschki, 1971. Para la imprenta napolitana, véase también Giuseppina Zappella, Tipografia campana del Cinquecento: centri e stampatori. Dizionario Storico-bibliografico, Quaderni dell'Accademia Pontaniana, Napoli, Francesco Giannini e figli, 1984, y Tobia R. Toscano, Contributo alla tipografia a Napoli nella prima metà del Cinquecento (1503-1553), Napoli, E.DI.SU, 1992.

45. Como escribe Curzio Mazzi, op. cit., t. I, p. 130, la principal producción de los Rozzi consistió en comedias y églogas «rusticali e villanesche».

46. Virgilio, Georgicas, Lib. II, vv. 1-6: «Hactenus arvorum cultus et sidera caeli; / nunc te, 
aprovechamiento de la égloga III de Nemesiano, un himno a Baco que, tras su educación y descubrimiento de la vid y el vino, concluye con una escena de sátiros ebrios que desenfrenadamente persiguen a las ninfas. A Baco se unía también Príapo, dios de la fertilidad y protector de los huertos, conformando de esta manera un sustrato y una tendencia erótico-agrícola que recorrerá todos los ambientes de la época, conectando además con determinadas costumbres locales relacionadas con el mundo de la agricultura. De esta manera, el «hortus» adquiere una connotación erótica convirtiéndose en una metáfora nuclear de amplio desarrollo.

A esta línea priapea, que por otro lado avala la tradición humanista, y que encaja en el contexto napolitano por su conocido culto al dios Príapo (recordemos las célebres fiestas de Piedigrotta), con su conexión con el mundo agrícola y del vino, se adscriben las Stanze di coltura sopra gli Horti delle donne de Luigi Tansillo ${ }^{47}$, redactadas hacia 1532-33, para circular manuscritas, impresas y reimpresas más allá del XVI, manifestación de un complejo itinerario de intervenciones textuales en el que no podemos detenernos aquí, pero que son signo evidente de su enorme éxito. Los mismos formatos de las impresas (fascículos cuando son independientes) hasta ahora conocidas lo reflejan también, pues se observa una sucesiva reducción de formatos de un cuarto a un doceavo. El título original, alternando con el de Il Vendemmiatore, "per adietro improprio nome intitolato», según reza el frontispicio de la edición veneciana de 1549 de Baldassarre Costantini, da cuenta también del carácter licencioso de dichas estancias, lo que no impediría su calificación como "piacevoli» o sencillamente «amorose». La dedicatoria a Jacopo Caraffa resulta sustanciosa a la hora de interpretar el sentido de estas estancias bucólico-agrícolas. Nacen estas, como práctica del ocio y del entretenimiento, enmarcadas en un contexto rural y en una costumbre tradicional y local como es la vendimia de Nola, donde en "questi di che sono consacrati a Baco» permiten hablar libremente. De ahí las referencias concretas a los vinos de la zona, que apelan a un clasicismo grecolatino, «il greco di Somma» o «i latini di Nola»; es decir, al sedimento literario (Teócrito y Virgilio) sobre el que confeccionará sus estancias moduladas en la expresividad satírica de los Sermones horacianos. De estos afloran determinados ecos, como la evocación priapea de la sátira VIII del libro I, donde el poeta latino da voz a un tronco de higuera convertido en el dios Príapo, o en la libertad de hablar que permiten las fiestas saturnales de la sátira 7, libro II. Pero en una proximidad cronológica no se descarta la huella del tratadillo De Nola Patria de Ambrogio Leone, publicado en Venecia en 1514, donde, entre otras costumbres locales, se describe pormenorizadamente el proceso de la vendimia en esta zona. Las Stanze nacen, como también se deduce de la dedicatoria, para

Bacche, [...] / [...] Huc, pater o Lenae tuis hic omnia plena / muneribus, tibi pampineo gravidus autumno / floret ager, spumat plenis vindemia labris», y vv. 274-6.

47. A falta de una edición moderna de Il Vendemmiatore, así como de Il Podere de Luigi Tansillo, con el que debe relacionarse, se recurre al texto de Francesco Flamini, L'egloga e i poemetti del Tansillo, op.cit. La edición de Jesús Graciliano González del Vendemmiatore (Matera, Edizioni La Bautta, 2006) sigue el texto de Flamini. 
difundirse en un circuito aristocrático, en su doble posibilidad de fruición: la lectura individual del destinatario o la recitación ante un público de «vaghi giovani» y «belle donne», según se explicita ya en los primeros versos por la interpelación a un auditorio femenino: "Giovane donne e belle, che sovente / date ai versi d'amor benigne orecchie; / perché voi siate alle mie voci intente / et io ne gli occhi vostri ognor mi specchie». Es la voz del poeta-autor y actor que convierte estas estancias en un acto performativo, en una égloga dramatizada donde el autor, «fatto di rustico uom colto poeta», se finge, como confiesa en la canción de arrepentimiento a Pablo IV, ser «rozzo villan sotto festose larve». Y como escribirá más tarde a Cola Maria Rocco (Capitolo XIX, vv. 304-6): «Io credo c'abbi visto quell'operetta, l là dove indusse quel vendemmiatore, I ch'asceso soura un arbor predicava / et facea del poeta e del cultore». Bajo este velamen hortelano (variante pastoril), el poeta/actor desgrana exhortativamente y en la clave erótica del hortus, una invitación de claros tonos ausonianos al goce sexual explicado a través de las técnicas y utillajes de la preparación y cultivo del huerto.

En este cauce galante del que nos advierte Tansillo existe una relación con determinadas prácticas lúdico-sociales que recogen los tratados o compendios, muy difundidos en esa cronología, sobre ciertos juegos como I cento ginochi de Innocenzo Ringhieri, donde precisamente figura uno sobre el hortelano, si bien exento de connotaciones eróticas. Pero, por su erotismo, las Stanze están más en la línea del canto "carnascialesco» toscano sienés, donde no faltan alusiones en doble sentido a costumbres y temas relativos a los vendedores de frutas y sembradores de hortalizas en los huertos femeninos. En Siena, y en esta misma línea erótico-hortelana, encontramos una correspondencia en el Giuoco degli Ortolani, practicado como entretenimiento por los jóvenes de la alta sociedad sienesa en la privacidad de sus casas, según describe retrospectivamente y en forma dialógica, Scipione Bargagli en sus Trattenimenti ${ }^{48}$. En él se finge cómo uno de ellos, en guisa de hortelano, concretamente de «fidelissimo ortolano» de una de las damas, llama a su puerta para venir con «il suo perfetto seme a seminare, come le avrà co' suoi buon ferri molto ben lavorate, le belle bracci [surcos] e fresche del vostro orto» ${ }^{49}$. No es difícil suponer que Tansillo tuviera conocimiento de estas prácticas sienesas, cuya fama, es decir, las famosas «veglie»" ${ }^{50}$, se extendía por toda Italia, por lo que a Nápoles pudo llegar posiblemente gracias al contacto con los Intronati. Nada extraño si consideramos que la Cecaria de Epicuro se inspira en el Giuoco dei Ciechi (Trattenimenti, p. 429-461).

48. Manejo la edición moderna de Scipione Bargagli, I trattenimenti, ed. Laura Riccò, Salerno Editrice, Roma, 1989. En la página 229 hay una sustanciosa nota sobre este juego.

49. I trattenimenti, op. cit., p. 241.

50. Estas veladas gentilicias vinculadas a la actividad de los Intronati fueron posteriormente recogidas en volumen por Girolamo Bargagli en 1572. Véase Girolamo Bargagli, Dialogo dei giuochi, ed. Patrizia d'Incalci Ermini, Siena, Accademia Senese Degli Intronati, 1982. En p. 111, se recoge el Giuoco della Cecaria (n. 65), que pudo haber influido también en la obra homónima del Epicuro. 
Paralelamente, si bien en una versión rústica, los académicos Rozzi cultivaron en análogos términos este tipo de contenidos en sus églogas, farsette o mascherate, "che cosi avessero una forma speciale di poesia erotica» ${ }^{51}$. Y, sobre todo, porque también esta vena rústica de dramatización de la égloga, desde sus primeros cultivadores (Francesco Fonsi, Veglia villanesca, impresa desde 1521 y 1547), según afirma L. Riccò ${ }^{52}$, había sido la responsable de la introducción en la literatura local de determinados juegos. Algunas de estas producciones, de hecho, circularon impresas, lo que supuso un próspero filón editorial. Del ya mencionado pre-rozzo Mescolino, por ejemplo, su Farsetta di KalendiMaggio, vinculada a la fiesta campesina, se realizaron diversas ediciones entre 1515-1549. Respecto a la circulación manuscrita, encontramos un testimonio evidente en el ms. H.XI.5 de la BCS, titulado Raccolta di Diverse Rime delli più Dotti Rozzi, un producto misceláneo de los académicos Rozzi, de difícil datación, pues no lleva fecha. Quizás al tratarse de una miscelánea recoja producciones de diferentes momentos. En este caso, podemos suponer un arco cronológico que oscilaría entre la década de los ' 30 , cuando los Rozzi son ya academia, y 1546, pues en él figura una «mascherata» contra Don Ferrante Gonzaga, que hace alusión al tiempo en que este tenía desplegadas sus tropas en Siena. En este manuscrito, bajo el título también de «mascherata», en el fol. 81 y ss., figura una Mascherata delli hortolani recitata da un martorello. Se trata de una versión análoga a la del juego mencionado, pero expresado en un lenguaje realista sembrado de dialectalismos y de carácter soez. El recitante, convertido en "ortolano» ("[...] e so' per dir el vero un Ortolano»), se dirige a un público femenino («Donne, s'havete voglia di sapere [...] / So'contento di farve un tal piacere [...]» para desgranar, en clave erótica y como exhortación a las damas («Donne mie belle galantine»), todo un plan de cultivo, incluyendo los utensilios propios para tal labor: "Non si restan, / per fin che non è pieno / di seme et allapato ogni cantone / col serchiel con la zappa é col piccone», porque "Prima bisogna per ogni catone / tener l'orto delicato e netto", y así hasta ofrecerles como fruto o medicina provechosa un hinojo o hierba emblemática en el sentido aludido (signo fálico), «che vi fa tornar l'appetito» y del que «la più principal», entre sus virtudes, es la de hacer «fra le donne sottili ingrossare». Es fácil suponer que se tratara de una "mascherata» de tiempo de carnaval intercalada quizás, como se señaló antes, en algunas de las representaciones dramáticas o veladas de los Intronati, precisamente por apelar a un público femenino en términos galantes. Pero en las Stanze de Tansillo, al tratarse de un autor "dolce e faceto», un lenguaje culto controla su erótico monólogo, de pormenorizada descripción, análoga a la de los ejemplos señalados, donde caben también guiños a ciertos aspectos de la tradición rural y licenciosa de la tradición latina. Me refiero a la calificación de estos versos como rimas "fescennine» ("E le rime chio canto, fescennine», estancias 36-40, redacción de 1534), que sugeriría esa presumible

51. Curzio Mazzi, op. cit., vol. I, pp. 130-31. Recuerda el crítico también que en 1533 la congrega introdujo la lectura de Sannazaro en prosa y verso (p. 113).

52. Cf. Laura Riccò, Giuoco e teatro nelle veglie di Siena, Roma, Bulzoni, 1993, p. 43. 
recitación con un acompańamiento musical a modo del "fescenino» clásico; esto es, la forma rudimentaria recitada/cantada por campesinos durante las fiestas rurales, consistente en un diálogo de carácter licencioso mencionado por Horacio (Epistulae II, 1, vv. 145-6). Por otra parte, aunque en esta cronología en la que escribe Tansillo los modelos del primitivo bucolismo sienés estén ya caducados, es posible también que aún resonaran en Il Vendemmiatore, por cierta vinculación temática (la vid) y por su marcado sensualismo, los ecos de la égloga primera de Arzocchi, justamente en esa escena bucólica en que Terinto contempla a la ninfa cogiendo la uva: "Vidi fral verde biancheggiar la gola / e lei rimasa sola [...] / [...] aprendo il riso, / co'denti l'ha inciso / e lego col finocchio il saracino». El hinojo, desvinculado ya de la vid, asume una connotación erótica en la citada «mascherata» de los Rozzi, y con esta misma intencionalidad, la menta, desde su propiedad afrodisíaca atribuída por Hipócrates, se convierte en hierba emblemática en la estancia 161 del Vendemmiatore (1534): «È dunque la miglior de l'altre piante, / O donne mie, la menta pargoletta», de la que dice, en la estancia LXIX (1532), no acordarse el nombre dado por "gli hortolan di Roma». Esta variante no es sino una muestra de la serie de concomitancias resultantes del cotejo entre ambos textos del que resulta más próximo al de los Rozzi la primera versión de 1532. En cualquier caso, puede asegurarse un seguimiento general por parte de Tansillo del modelo sienés, a juzgar por la pormenorizada descripción en clave erótica en todo el desarrollo de $I l$ Vendemmiatore, que refiere la preparación de los huertos, su forma y periodicidad de riego, de depositar la semilla al trazado de los surcos, la necesidad de eliminar las malas hierbas, y, por supuesto, la enumeración de los utensilios adecuados, que, en definitiva, resumen el trabajo del hortelano como metáfora del ritual sexual. Basten algunos ejemplos donde se evidencian paralelismos, coincidencias de locuciones o palabras en rima. El primero se refiere a la periodicidad del riego y limpieza de los huertos:

Rozzi: «Prima bisogna per ogni cantone / tener l'orto delicato e netto [...] Però bisogna tener notte e giorno / netti gli orti dall'herbe ch'hanno intorno" " ${ }^{53}$; véase Tansillo, estancia XLVI (1532): «Spargasi l'acqua agl'orti entro e dintorno / al men tre volte, fra la notte e il giorno».

Algo más distanciado es el ejemplo que sigue, si bien permaneciendo en la misma idea:

Rozzi: «Siam persone da farvi el dovere / et se ci date a logorar l'orto / vel'empirem di seme in tempo corto / e di tutte le cose ch'ho cantato / so deliberato del paragon mostrarvi»; véase Tansillo en la estancia LXX $(162,1534)$ : «Essil diranno: ma per farvi liete, / I've la mostrerrò, se voi volete» o, en XLIX (1532): "Deh, se quell'acqua di che lieto ognora I bagno la terra ov'io vo' far semenza / provaste care donne, una sol ora [...] / ne brameresti far l'esperienza?».

53. Las citas de los Rozzi proceden del ya mencionado Ms.H.XI.5: Raccolta di Diverse Rime delli piu dotti Rozzi. 
Y, poco más adelante, en la estancia LI (1532), Tansillo recupera la rima en $-i o$, que el texto de los Rozzi ha utilizado en los versos inmediatamente anteriores ("Ma per tornar al proposito mio / [...] se volete che costoro et io / [...] chel vel giuro pel corpo del mio zio»): "Ma perché rade volte uman desio / [...] / senza soccorso d'alcun nume pio / [...] Onde ciascun fa maggior preghi al dio».

$\mathrm{Y}$, por último, respecto al ofrecimiento de la hierba benefactora, mientras los Rozzi esgrimen el hinojo y sus propiedades erótico-terapéuticas, Tansillo lo hace con la menta:

Rozzi: «Perché rallegra il cuor solo a vederla / O pensateci di poi a possederla [...] et chi avesse lo stomaco stanco / chesto finochio ve lo fa partire [...] Chesto vi fa tornar l'appetito I tant'è dolce soave e saporito [...] Et per concluder tal finocchio giova». Véase Tansillo LXVI (1532): "Donzella, che solinga abbia paura [...] / Tenga quest'erba in seno, e stia sicura [...] Mangi quest'erba che rallegra il core». Y siguiendo en la estancia LXVII: «E se stomaco avesse freddo e stanco, / Lo scalda e lo rinforza al digerire [...] Che tanto a fredde quant 'a calde giova".

Concluyo aquí este trazado de la evolución de la égloga vulgar, en la que, como se observa, Siena obtuvo un papel de relavancia, más allá de la edición Miscomini. 
